\title{
Implementasi Artificial Intelligence pada Game Defender of Metal City dengan Menggunakan Finite State Machine
}

\author{
Billy, Imam Kuswardayan, Wijayanti Nurul Khotimah \\ Departemen Teknik Informatika, Fakultas Teknologi Informasi, Institut Teknologi Sepuluh Nopember \\ (ITS) \\ e-mail:imam@its.ac.id
}

\begin{abstract}
Abstrak-Game adalah jenis perangkat lunak yang populer dewasa ini. Pada game biasa terdapat Artificial Inteligence (AI) yang mengendalikan pihak komputer sehingga manusia yang bermain dapat merasakan seolah mereka sedang melawan pemain manusia lain saat bermain. Salah satu jenis game yang ada ialah tower defense dimana pemain perlu mempertahankan tower atau markas nya agar tidak dihancurkan oleh pihak lawan. Untuk membuat AI untuk game berjenis tower defense, diperlukan algoritma yang baik untuk mengatur gerakan pasukan lawan. Penelitian ini mengusulkan penerapan AI pada game berjenis tower defense menggunakan rule based Finite State Machine. Setiap pasukan memiliki AI dengan beberapa state, pada saat terjadi suatu kondisi tertentu, maka pasukan akan berpindah dari satu state ke state lainnya berdasarkan rule yang telah ditentukan, hanya ada satu state yang bisa aktif pada suatu waktu. Pada penelitian ini AI akan dibagi menjadi 3 level yaitu easy, medium dan hard. Pengujian dilakukan dengan mempertandingkan antar level AI pada semua kemungkinan tingkat kesulitan, lalu dibuat tabel derajat kemenangan atau winning rate dari AI yang ada. Berdasarkan hasil pengujian Finite State Machine dapat diterapkan pada game berjenis tower defense dengan baik untuk membentuk AI yang kuat.
\end{abstract}

Kata Kunci-Game, Artificial Intelligence, Tower Defense, Unity.

\section{PENDAHULUAN}

$\mathrm{P}$ ERKEMBANGAN teknologi yang sangat pesat akhir-akhir ini membawa banyak perubahan dalam perkembangan perangkat lunak, salah satu jenis perangkat lunak yang sangat popular dewasa ini adalah game, game merupakan perangkat lunak yang digunakan sebagai sarana hiburan baik oleh kaum anak-anak ataupun orang dewasa.

Salah satu fitur yang umum dan dapat ditemui pada hampir semua game yang ada pada zaman sekarang adalah Artificial Intelligence atau AI, AI adalah kepintaran buatan yang dipasang pada sistem computer sehingga memungkinkan pemain untuk bermain melawan komputer dengan keadaan seolah-olah ia melawan pemain lain, membuat AI adalah suatu tantangan tersendiri bagi developer game.

Finite State Machine atau FSM adalah sebuah model yang digunakan untuk menggambarkan alur dari suatu proses berdasarkan state atau keadaan dari suatu proses. Hanya ada satu state yang bisa aktif pada suatu waktu sehingga dibutuhkan adanya perpindahan ke state lain apabila ingin melakukan aksi yang lain[1]. FSM biasa digunakan untuk mengatur dan menentukan alur tindakan, yang berguna untuk mengimplementasikan AI dalam game.

Defender of Metal City adalah game berjenis tower defense yang dirancang dengan AI untuk meningkatkan antusiasme pemain dengan adanya lawan AI dengan tingkat kesulitan yang sepadan.

Pada penelitian ini akan mengimplementasikan AI pada game berjenis tower defense menggunakan Finite State Machine. Penelitian ini dibagi menjadi beberapa tahap. Tahap pertama, merancang game dengan genre tower defense dan aturan permainannya. Kedua, merancang strategi untuk memenangkan game. Ketiga, mengimplementasikan strategi untuk menang dan Finite State Machine pada AI serta perancangan level AI. Langkah terakhir, akan dilakukan uji coba terhadap kemampuan AI dengan mempertandingkan antar setiap kemungkinan tingkat kesulitan $A I$.

\section{TINJAUAN PUSTAKA}

\section{A. Artificial Intelligence}

Artificial Intelligence atau Kecerdasan Buatan adalah kecerdasan yang dimiliki oleh mesin yang dapat bertindak seperti layaknya manusia[1]. Pada game, AI bertindak dalam mengendalikan komputer agar dapat bermain melawan pemain manusia.

\section{B. Tower Defense}

Tower defense adalah sub-genre dari game real-time strategy dimana tujuan utama pemain adalah melindungi tower utamanya dari serangan musuh dengan menempatkan pertahanan di sepanjang jalan menuju tower tersebut, apabila musuh berhasil menghancurkan tower milik pemain maka pemain akan kalah[2]. Beberapa contoh game berjenis tower defense antara lain adalah Kingdom Rush dan Bloons TD.

\section{Finite State Machine}

Finite State Machine atau FSM adalah sebuah model yang digunakan untuk menggambarkan alur dari suatu proses berdasarkan state atau keadaan dari suatu proses, hanya ada satu state yang bisa aktif pada suatu waktu sehingga dibutuhkan adanya perpindahan ke state lain apabila ingin melakukan aksi yang lain[3].

FSM biasa digunakan untuk mengatur dan menentukan alur tindakan, yang berguna untuk mengimplementasikan AI dalam 
game. Contoh FSM yang digunakan sebagai AI dari musuh pada game dapat dilihat pada Gambar $\mathbf{1}$.

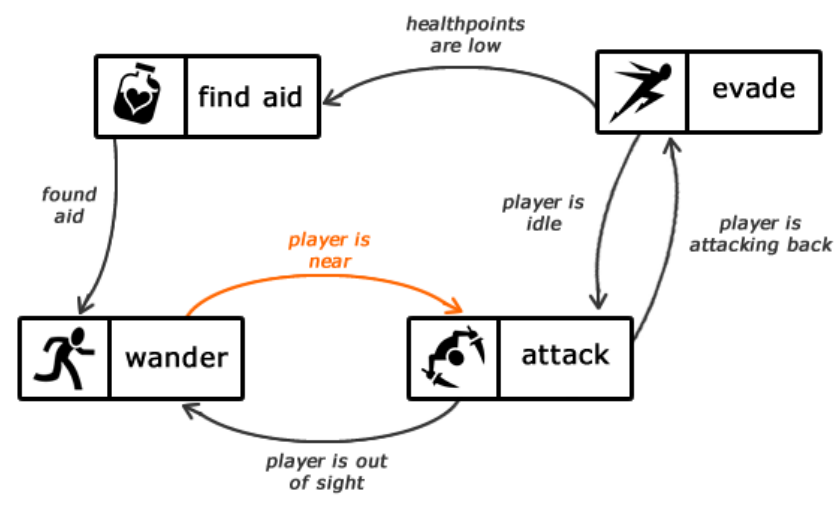

Gambar 1. Contoh Penggunaan FSM dalam AI pada Game

\section{Unity}

Unity adalah sebuah Game Engine Cross-platform yang dapat menghasilkan game untuk berbagai macam platform termasuk Windows, Mac, Linux, Android, iOS, dan banyak lagi. Unity pertama kali diterbitkan pada Tahun 2005 dan telah banyak berkembang sejak saat itu. Unity memiliki Built-in IDE yang bermana MonoDevelop.

\section{DESAIN SISTEM}

\section{A. Spesifikasi Game}

Pada game ini terdapat dua pihak yang saling menyerang satu sama lain, target nya adalah menghancurkan tower lawan sementara mempertahankan agar tower nya sendiri jangan sampai hancur, pihak yang towernya hancur akan kalah.

Pada game ini terdapat 4 jenis pasukan yang sama pada kedua belah pihak, yaitu minion, warrior, ranger, dan artillery. Pada game ini kedua belah pihak berusaha saling menyerang Tower milik pihak lawan.

Peraturan game adalah sebagai berikut:

1. Terdapat 2 belah pihak yang saling menyerang satu sama lain.

2. Terdapat 4 jenis pasukan berbeda pada setiap pihak yang memiliki kemampuannya sendiri-sendiri.

3. Terdapat tower pada kedua belah pihak yang apabila hancur maka pihak tersebut akan kalah.

4. Tower dapat menyerang pasukan musuh yang mendekat

5. Apabila membunuh pasukan milik musuh maka akan mendapat sejumlah uang.

6. Kedua pihak memiliki pilihan untuk meng-upgrade pasukan yang dimilikinya agar lebih kuat hingga level 3, dengan setiap upgrade membutuhkan biaya sejumlah uang.

7. Kedua belah pihak memiliki pilihan untuk membuat pasukan elite yaitu pasukan yang jauh lebih kuat dari pasukan biasa dengan membayar sejumlah uang.

8. Terdapat 3 tingkat kesulitan pada game yaitu easy, medium, dan hard, pemain dapat memilih akan melawan AI dengan tingkat kesulitan mana dan akan menggunakan tingkat kesulitan mana untuk AI pada pihak pemain itu sendiri.
Terdapat 4 jenis pasukan pada game ini yaitu:

1. Minion

Tipe pasukan terlemah, memiliki damage yang kecil, dapat bergerak dan menyerang dengan cepat, hanya dapat menyerang dari jarak dekat dan memiliki health point yang sedikit.

2. Warrior

Tipe pasukan yang bergerak dengan kecepatan sedang, memiliki health point yang cukup sehingga dapat menyerang lawan dari jarak dekat, dan juga memiliki damage dan kecepatan menyerang yang lebih besar daripada tipe minion.

3. Ranger

Tipe pasukan yang menyerang dari jarak jauh, memiliki damage dan health point yang lebih besar daripada tipe minion tetapi masih lebih kecil daripada tipe warrior sehingga tidak dapat menyerang dari jarak dekat, bergerak dan menyerang dengan kecepatan yang sama dengan tipe warrior.

4. Artillery

Tipe pasukan terkuat yang memiliki area damage sehingga dapat menyerang beberapa musuh secara bersamaan, memiliki damage dan health point paling besar diantara semua pasukan namun kecepatan serangan dan kecepatan bergeraknya adalah yang paling lambat diantara semua tipe pasukan yang lain.

Pasukan akan diproduksi oleh tower secara periodik sehingga pasukan akan terus dihasilkan. Namun untuk pasukan elite, pemain harus mengendalikan kapan akan membeli pasukan elite yang mana karena pembelian pasukan elite harus menggunakan uang.

Pasukan dapat berjalan di map pada area yang bukan hutan. Pemain juga dapat mengendalikan pergerakan pasukan dengan kontrol menggunakan mouse untuk mengatur kemana pasukan harus pergi atau pasukan musuh mana yang harus diserang.

Kondisi kemenangan game adalah menghancurkan tower milik lawan. Kondisi kekalahan game adalah saat tower milik pemain dihancurkan oleh lawan.

\section{B. Strategi Memenangkan Permainan}

Strategi memenangkan game adalah dengan mengatur agar pasukan dapat seoptimal mungkin membunuh sebanyak mungkin musuh sehingga dapat terus maju sehingga pada akhirnya menyerang tower musuh. Juga harus diperhatikan pertahanan terhadap tower sendiri karena apabila tower hancur maka pemain akan kalah tidak peduli berapa banyak pasukan musuh yang telah dibunuhnya.

Karena setiap pasukan memiliki kemampuan yang berbedabeda maka penggunaan setiap pasukan juga berbeda-beda:

1. Pasukan tipe minion memiliki damage yang tidak terlalu besar namun dapat bergerak cepat sehingga dapat dimanfaatkan untuk membunuh pasukan yang sudah lemah atau health point nya tersisa sedikit.

2. Pasukan tipe warrior dapat digunakan sebagai garis depan karena memiliki pertahanan dan damage yang lumayan sehingga dapat melawan musuh. 
3. Pasukan tipe ranger dapat menyerang dari jarak jauh sehingga dapat digunakan sebagai backup dari belakang.

4. Pasukan tipe artillery dapat digunakan untuk melawan musuh dalam jumlah banyak karena dapat melakukan area damage.

Untuk strategi mengatur kapan melakukan upgrade pasukan dan men-deploy elite pasukan, upgrade harus dilakukan terlebih dahulu karena upgrade bersifat permanen, apabila semua pasukan telah di upgrade hingga level tertinggi, barulah uang yang tersisa digunakan untuk menghasilkan pasukan elite.

\section{Penerapan Artificial Intelligence}

Tahap penerapan artificial intelligence dibagi menjadi beberapa bagian, yaitu:

\section{Penerapan AI pada Tower}

Tower adalah bagian penting dalam game karena apabila tower hancur, pihak tersebut kalah, pada tower, hanya ada 2 keadaan, idle yaitu tidak melakukan apapaun, atau attack yaitu menyerang dengan menembakkan panah pada saat ada musuh mendekat dengan jarak kurang dari sama dengan 30 meter.

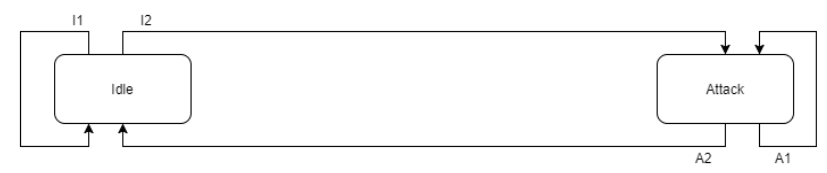

Gambar 2. FSM pada Tower

FSM yang digunakan oleh tower dapat dilihat pada Gambar 2. Penjelasan untuk kondisi perpindahan state pada FSM pada tower dapat dilihat sebagai berikut:

I1, A2. Tidak ada musuh dalam jarak 30 meter.

I2, A1. Ada musuh dalam jarak 30 meter.

Semua angka jarak yang berbeda-beda didapat dari hasil percobaan. Dari beberapa kemungkinan angka yang telah dicoba telah disimpulkan bahwa angka - angka yang didapat adalah angka yang terbaik untuk menghasilkan AI tower yang kuat.

\section{Penerapan Tingkat Kesulitan AI}

Pada game ini terdapat 3 tingkat kesulitan AI, yaitu easy, medium, dan hard. Terdapat beberapa hal yang membedakan ketiga tingkat kesulitan tersebut.

Pada ketiga tingkat kesulitan yang berbeda, terdapat delay saat mengambil keputusan, pada tingkat kesulitan easy, pengambilan keputusan dilakukan setiap 50 frame. Pada tingkat kesulitan medium, pengambilan keputusan dilakukan setiap 25 frame. Pada tingkat kesulitan hard, pengambilan keputusan dilakukan setiap 1 frame.

Pada ketiga tingkat kesulitan, juga terdapat kemungkinan pengambilan keputusan secara random, dimana AI akan bertindak secara random dan tidak mengikuti rule-base yang telah ditetapkan, semakin rendah tingkat kesulitan AI maka akan semakin tinggi kemungkinan pengambilan keputusan secara random tersebut. Pada tingkat kesultian hard, tidak ada kemungkinan keputusan random. Pada tingkat kesulitan medium, terdapat $15 \%$ kemungkinan pengambilan keputusan random. Pada tingkat kesulitan easy, terdapat 30\% kemungkinan pengambilan keputusan random. Pada tingkat medium, terdapat 4 kemungkinan keputusan random yang dapat diambil, yaitu bergerak secara random, pulang kembali ke tower, mengikuti teman secara random, dan menyerang musuh secara random. Pada tingkat kesulitan easy hanya terdapat 3 kemungkinan keputusan random, yaitu bergerak secara random, pulang kembali ke tower, dan mengikuti teman secara random.

Pada bagian pengambilan keputusan untuk meng-upgrade pasukan atau men-deploy pasukan elite, juga terdapat perbedaan. Pada tingkat kesulitan easy, pengambilan keputusan dilakukan secara random total. Pada tingkat medium, akan dilihat apabila ada jenis pasukan yang belum mencapai level maksimal, maka ada 70\% kemungkinan pasukan tersebut akan di-upgrade terlebih dahulu, dan $30 \%$ sisanya adalah kemungkinan mengeluarkan pasukan elite secara random. Pada tingkat kesulitan hard, pasukan akan selalu di-upgrade terlebih dahulu hingga mencapai level maksimal, barulah berikutnya akan mengeluarkan pasukan elite secara random.

Semua angka presentase kemungkinan dan jumlah frame untuk semua tingkat kesulitan yang berbeda-beda didapat dari hasil percobaan. Dari beberapa kemungkinan angka yang telah dicoba telah disimpulkan bahwa angka - angka yang didapat adalah angka yang terbaik untuk menghasilkan AI yang sesuai dengan tingkat kesulitannya.

\section{Penerapan AI Pasukan Minion}

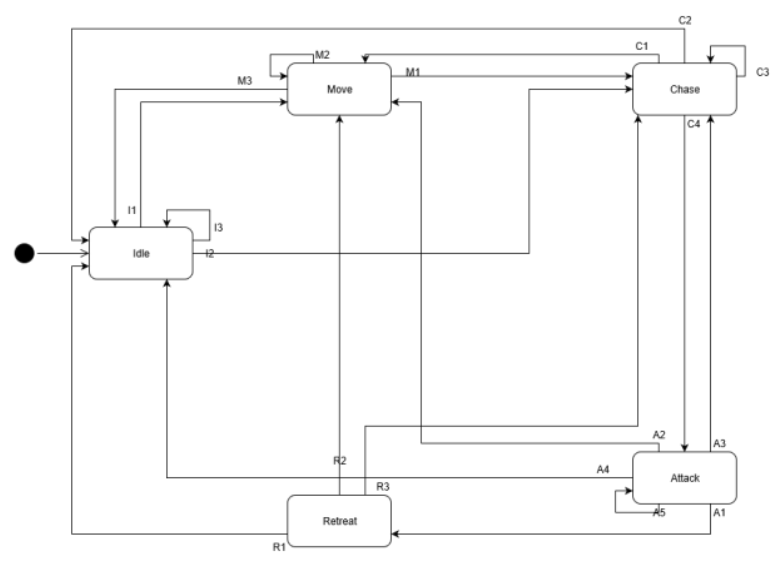

Gambar 3. FSM pada Pasukan Minion

FSM pasukan minion dapat dilihat pada Gambar 3. Penjelasan untuk kondisi perpindahan state pada FSM pada pasukan minion dapat dilihat sebagai berikut:

I1, M2, R2, C1. Salah satu kondisi berikut terpenuhi:

- Health point lebih dari $25 \%$, tidak ada musuh dalam jarak 20 meter.

- Health point kurang dari sama dengan $25 \%$, dalam jarak 20 meter ada 5 atau lebih teman.

I2, M1, R3, C3. Salah satu kondisi berikut terpenuhi:

- Health point lebih dari $25 \%$, ada musuh tipe ranger.

- Heallth point lebih dari $25 \%$, tidak ada musuh tipe ranger. 
- Health point kurang dari sama dengan $25 \%$, dalam jarak 20 meter ada 5 atau lebih teman dan ada musuh dalam jarak 15 meter.

I3, R1, C2, M3. Health point kurang dari $25 \%$.

C4. Jarak target kurang dari sama dengan 3 meter.

A1. Salah satu kondisi berikut terpenuhi:

- Health point kurang dari $25 \%$, musuh tipe minion atau warrior, tidak ada 5 atau lebih teman tipe minion dalam 20 meter dan health kurang dari health point musuh.

- Health point pemain kurang dari $25 \%$, musuh tipe ranger, health point musuh lebih dari sama dengan $50 \%$.

- Health point pemain kurang dari 25\%, musuh tipe artillery, health point musuh lebih dari health point pemain.

A2. Salah satu kondisi berikut terpenuhi:

- Target mati atau hilang, health point lebih dari $25 \%$, tidak ada musuh dalam jarak 20 meter.

- Musuh mati atau hilang, health point kurang dari sama dengan 25\%, dalam jarak 20 meter ada 5 atau lebih teman.

A3. Salah satu kondisi berikut terpenuhi:

- Target mati atau hilang, health point lebih dari $25 \%$, ada musuh tipe ranger.

- Target mati atau hilang, health point lebih dari $25 \%$, tidak ada musuh tipe ranger.

- Target mati atau hilang, health point kurang dari sama dengan $25 \%$, dalam jarak 20 meter ada 5 atau lebih teman dan ada musuh dalam jarak 15 meter.

A4. Target mati atau hilang, health point kurang dari $25 \%$.

A5. Salah satu kondisi berikut terpenuhi:

- Health point lebih dari $25 \%$.

- Health point kurang dari sama dengan $25 \%$, musuh tipe minion atau warrior, dalam jarak 20 meter. terdapat 5 atau lebih teman tipe minion.

- Health point kurang dari sama dengan $25 \%$, musuh tipe minion atau warrior, health point musuh lebih kecil dari health point pemain.

- Health point pemain kurang dari $25 \%$, musuh tipe ranger, health point musuh kurang dari 50\%.

- Health point pemain kurang dari $25 \%$, musuh tipe artillery, dan health point musuh kurang dari health point pemain.

Semua angka presentase health point dan jarak yang berbeda-beda didapat dari hasil percobaan. Dari beberapa kemungkinan angka yang telah dicoba telah disimpulkan bahwa angka - angka yang didapat adalah angka yang terbaik untuk menghasilkan AI pasukan minion yang kuat.

\section{Penerapan AI Pasukan Warrior}

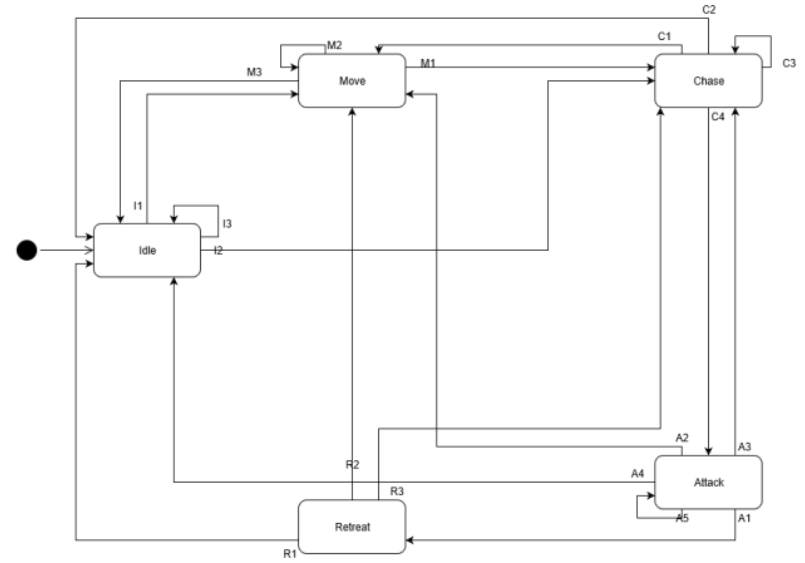

Gambar 4. FSM pada Pasukan Warrior

FSM pasukan warrior dapat dilihat pada Gambar 4. Penjelasan untuk kondisi perpindahan state pada FSM pada pasukan warrior dapat dilihat sebagai berikut:

I1, R2, C1, M2. Salah satu kondisi berikut terpenuhi:

- Health point lebih dari $20 \%$, tidak ada musuh dalam jarak 20 meter.

- Health point kurang dari sama dengan $20 \%$, ada 5 atau lebih teman dalam jarak 20 meter dan ada musuh dalam jarak 20 meter, tidak ada musuh dalam jarak 20 meter.

- Health point kurang dari sama dengan $20 \%$, ada 5 atau lebih teman tipe minion dalam jarak 20 meter, tidak ada musuh dalam jarak 20 meter.

I2, M1, R3, C3. Salah satu kondisi berikut terpenuhi:

- Health point lebih dari $20 \%$, ada musuh dalam jarak 20 meter.

- Health point kurang dari sama dengan $20 \%$, ada 5 atau lebih teman tipe warrior atau ranger dalam jarak 20 meter dan ada musuh dalam jarak 20 meter.

- Health point kurang dari sama dengan $20 \%$, ada 5 atau lebih teman tipe minion dalam jarak 20 meter dan ada musuh dalam jarak 20 meter.

- Health point kurang dari $20 \%$, tidak ada teman dalam jarak 20 meter, ada musuh tipe minion atau ranger.

I3, M3, R1, C2. Health point kurang dari $20 \%$, tidak ada 5 atau lebih teman dalam jarak 20 meter, tidak ada musuh tipe minion atau ranger.

C4. Jarak target kurang dari sama dengan 3 meter.

A1. Salah satu kondisi berikut terpenuhi:

- Health point pemain kurang dari $20 \%$, musuh tipe warrior atau ranger, tidak ada teman dalam jarak 15 meter, dan health point musuh lebih dari health point pemain.

- Health point pemain kurang dari $20 \%$, musuh tipe artillery, tidak ada teman dalam jarak 15 meter, dan health point musuh lebih dari health point pemain.

A2. Salah satu kondisi berikut terpenuhi:

- Target mati atau hilang, health point lebih dari $20 \%$, tidak ada musuh dalam jarak 20 meter.

- Target mati atau hilang, health point kurang dari sama dengan $20 \%$, ada 5 atau lebih teman dalam jarak 20 
meter dan ada musuh dalam jarak 20 meter, tidak ada musuh dalam jarak 20 meter.

- Target mati atau hilang, health point kurang dari sama dengan $20 \%$, ada 5 atau lebih teman tipe minion dalam jarak 20 meter, tidak ada musuh dalam jarak 20 meter.

A3. Salah satu kondisi berikut terpenuhi:

- Target mati atau hilang, health point lebih dari $20 \%$, ada musuh dalam jarak 20 meter.

- Target mati atau hilang, health point kurang dari sama dengan $20 \%$, ada 5 atau lebih teman tipe warrior atau ranger dalam jarak 20 meter dan ada musuh dalam jarak 20 meter.

- Target mati atau hilang, health point kurang dari sama dengan $20 \%$, ada 5 atau lebih teman tipe minion dalam jarak 20 meter dan ada musuh dalam jarak 20 meter.

- Target mati atau hilang, health point kurang dari $20 \%$, tidak ada teman dalam jarak 20 meter, ada musuh tipe minion atau ranger.

A4. Target mati atau hilang, health point kurang dari $20 \%$, tidak ada 5 atau lebih teman dalam jarak 20 meter, tidak ada musuh tipe minion atau ranger.

A5. Salah satu kondisi berikut terpenuhi:

- Health point lebih dari $20 \%$.

- Health point kurang dari $20 \%$, musuh tipe minion.

- Health point kurang dari $20 \%$, musuh tipe ranger atau warrior, dalam 15 meter ada 5 atau lebih teman tipe warrior atau ranger.

- Health point kurang dari $20 \%$, musuh tipe ranger atau warrior, dalam 15 meter ada 5 atau lebih teman tipe minion.

- Health point pemain kurang dari $20 \%$, musuh tipe ranger atau warrior, health point musuh kurang dari health point pemain.

- Health point pemain kurang dari $20 \%$, musuh tipe artillery, health point musuh kurang dari health point pemain.

Semua angka presentase health point dan jarak yang berbeda-beda didapat dari hasil percobaan. Dari beberapa kemungkinan angka yang telah dicoba telah disimpulkan bahwa angka - angka yang didapat adalah angka yang terbaik untuk menghasilkan AI pasukan warrior yang kuat.

\section{Penerapan AI Pasukan Ranger}

FSM pasukan ranger dapat dilihat pada Gambar 5. Penjelasan untuk kondisi perpindahan state pada FSM pada pasukan ranger dapat dilihat sebagai berikut:

I1, M2, F5, R3, C4. Health point kurang dari sama dengan $20 \%$ dan ada musuh dalam jarak kurang dari 5 meter.

I2, R2, M5, F2, C1. Health point lebih dari sama dengan 50\%, tidak ada musuh dalam jarak 30 meter.

I3, M1, F3, R4, C5. Health point lebih dari 20\% dan kurang dari 50\%, dan ada teman tipe warrior atau artillery.

I4, M3, F4, R5, C3. Salah satu kondisi berikut terpenuhi:

- Health point lebih dari sama dengan 50\%, ada musuh dalam jarak 30 meter.
- Health point kurang dari $20 \%$ dan ada musuh dalam jarak lebih dari 5 meter dan kurang dari 30 meter.

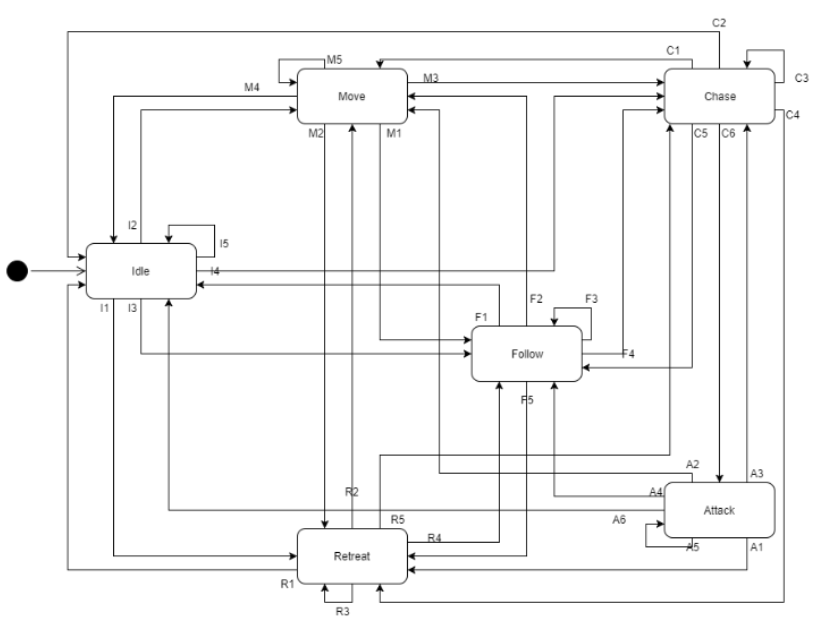

Gambar 5. FSM pada Pasukan Ranger

I5, M4, R1, F1, C2. Salah satu kondisi berikut terpenuhi:

- Health point lebih dari $20 \%$ dan kurang dari $50 \%$, dan tidak ada teman tipe warrior atau artillery.

- Health point kurang dari $20 \%$.

C6. Jarak target kurang dari 30 meter.

A1. Salah satu kondisi berikut terpenuhi:

- Jarak target kurang dari 5 meter.

- Target mati atau hilang, health point kurang dari sama dengan $20 \%$ dan ada musuh dalam jarak kurang dari 5 meter.

A2. Target mati atau hilang, health point lebih dari sama dengan 50\%, tidak ada musuh dalam jarak 30 meter.

A3. Salah satu kondisi berikut terpenuhi:

- Target mati atau hilang, health point lebih dari sama dengan 50\%, ada musuh dalam jarak 30 meter.

- Target mati atau hilang, health point kurang dari $20 \%$ dan ada musuh dalam jarak lebih dari 5 meter dan kurang dari 30 meter.

A4. Target mati atau hilang, health point lebih dari $20 \%$ dan kurang dari 50\%, dan ada teman tipe warrior atau artillery.

A5. Jarak target lebih dari 5 meter dan kurang dari 30 meter

A6. Salah satu kondisi berikut terpenuhi:

- Health point lebih dari $20 \%$ dan kurang dari $50 \%$, dan tidak ada teman tipe warrior atau artillery.

- Target mati atau hilang, health point kurang dari $20 \%$.

Semua angka presentase health point dan jarak yang berbedabeda didapat dari hasil percobaan. Dari beberapa kemungkinan angka yang telah dicoba telah disimpulkan bahwa angka - angka yang didapat adalah angka yang terbaik untuk menghasilkan AI pasukan ranger yang kuat. 


\section{Penerapan AI Pasukan Artillery}

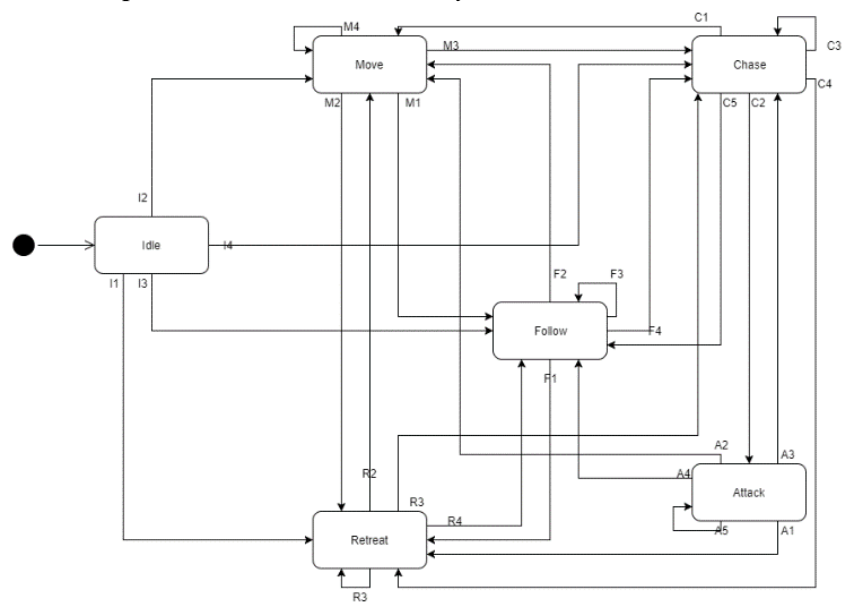

Gambar 6. FSM pada Pasukan Artillery

FSM pasukan artillery dapat dilihat pada Gambar 6. Penjelasan untuk kondisi perpidahan state pada FSM pada pasukan tipe artillery dapat dilihat sebagai berikut:

I1, M2, F1, R3, C4. Health point kurang dari 10\%, tidak ada 5 atau lebih teman dalam jarak 10 meter.

I2, R2, M4, C1, F2. Salah satu kondisi berikut terpenuhi:

- Health point lebih dari $20 \%$, tidak ada musuh dalam jarak 10 meter.

- Health point lebih dari $10 \%$ dan kurang $20 \%$, tidak ada musuh dalam jarak 10 meter.

I3, F3, M1, R4, C5. Health point kurang dari 10\%, dalam jarak 10 meter ada 5 atau lebih teman.

I4, M3, F4, C3, R3. Salah satu kondisi berikut terpenuhi:

- Health point lebih dari $20 \%$, ada musuh dalam jarak $20 \%$.

- Health point lebih dari $10 \%$ dan kurang $20 \%$, ada musuh dalam jarak 10 meter.

C2. Jarak musuh kurang dari sama dengan 5 meter.

A1. Health point kurang dari $10 \%$, tidak ada 5 atau lebih teman dalam jarak 10 meter.

A2. Salah satu kondisi berikut terpenuhi:

- Target mati atau hilang, health point lebih dari $20 \%$, tidak ada musuh dalam jarak 10 meter.

- Target mati atau hilang, health point lebih dari $10 \%$ dan kurang $20 \%$, tidak ada musuh dalam jarak 10 meter.

A3. Salah satu kondisi berikut terpenuhi:

- Health point kurang dari $20 \%$ dan lebih dari $20 \%$, musuh tipe artillery dengan health point lebih dari pemain, ganti target ke tipe minion atau ranger atau warrior terlemah.

- Health point kurang dari $10 \%$, ada 5 atau lebih teman dalam jarak 10 meter.

- Target mati atau hilang, health point lebih dari $20 \%$, ada musuh dalam jarak 20 meter.

- Target mati atau hilang, health point lebih dari $10 \%$ dan kurang 20\%, ada musuh dalam jarak 10 meter.

A4. Target mati atau hilang, health point kurang dari $10 \%$, dalam jarak 10 meter ada 5 atau lebih teman.

A5. Salah satu kondisi berikut terpenuhi:

- Health point lebih dari $10 \%$.
- Health point kurang dari $20 \%$ dan lebih dari $10 \%$, musuh tipe warrior, ranger, atau minion.

- Health point kurang dari $20 \%$ dan lebih dari $20 \%$, musuh tipe artillery dengan health point kurang dari pemain.

Semua angka presentase health point dan jarak yang berbeda-beda didapat dari hasil percobaan. Dari beberapa kemungkinan angka yang telah dicoba telah disimpulkan bahwa angka - angka yang didapat adalah angka yang terbaik untuk menghasilkan AI pasukan artillery yang kuat.

\section{UJI COBA}

Pengujian dilakukan dengan mempertandingkan AI melawan AI pada semua kemungkinan map dan tingkat kesulitan dengan mencatat hasil kemenangan dan waktu yang dibutuhkan untuk permainan selesai. Berdasarkan pengujian yang telah dilakukan, maka winning rate AI dapat dirangkum pada Tabel 1.

Tabel 1.

Winning Rate AI

\begin{tabular}{llll}
\hline \hline & Easy & Medium & Hard \\
\hline Easy & $40 \%$ & $13.333 \%$ & $0 \%$ \\
Medium & - & $53.333 \%$ & $0 \%$ \\
Hard & - & - & $46.667 \%$ \\
\hline \hline
\end{tabular}

\section{KESIMPULAN}

1. Penggunaan Finite State Machine dalam game berjenis tower defense yang dikombinasikan dengan strategi untuk menang dan aturan game dapat membentuk AI yang kuat.

2. AI yang memiliki tingkat kemungkinan tindakan random yang rendah akan lebih kuat daripada AI yang memiliki kemungkinan tindakan random yang lebih tinggi.

3. AI yang terbentuk telah sesuai dengan tingkat kesulitannya, dimana AI yang lebih susah akan memiliki kemungkinan kemenangan yang lebih besar.

\section{DAFTAR PUSTAKA}

[1] "Finite-State Machines: Theory and Implementation," Game Development Envato Tuts+. [Online]. Available: https://gamedevelopment.tutsplus.com/tutorials/finite-state-machinestheory-and-implementation--gamedev-11867. [Accessed: 12-Feb-2017].

[2] "What is Artificial Intelligence (AI)? - Definition from Techopedia," Techopedia.com. [Online]. Available: https://www.techopedia.com/definition/190/artificial-intelligence-ai. [Accessed: 12-Feb-2017].

[3] "Game Genres Defined: Tower Defense," Vita Player - the one-stop resource for PS Vita owners. [Online]. Available: http://www.vitaplayer.co.uk/game-genres-defined-tower-defense/. [Accessed: 12-Feb-2017]. 